\title{
Aagje Swinnen and John A. Stotesbury (eds.) (2012). Aging, Performance and Stardom: Doing Age on the Stage of Consumerist Culture. Berlin: LIT Verlag, 208 pp. ISBN 9783643901767 (paperback)
}

\author{
REVIEWED by KARIN LÖVGREN ${ }^{1}$
}

This second volume in the series Aging studies in Europe deals with performances in film, television and theatre. The chapters analyse cultural productions ranging from the film The Mother (2003) to the televised hidden camera show Benidorm Bastards (2010). The former is a much talked about movie, in which May, in her sixties, comes to London after her husband's death and begins a love and sexual relationship with a younger man, her daughter's boyfriend. From a psychoanalytic framework Ann Kaplan analyses how the reception and criticism of the movie dealt with the age differences in the relationship as well as with gendered role expectations of women, especially mothers. Benidorm Bastards is a format exported to several European countries. In the show, pensioners are cast in different situations which are meant to be provoking for the unwitting bystanders, mostly young people. In her introduction to the book Aagje Swinnen discusses different interpretations of the show. In other chapters adverts are examined, discussing representations of age and ageing in a commercial culture.

\footnotetext{
${ }^{1}$ Karin Lövgren, Umeå University, Sweden
} 
International Journal of Ageing and Later Life

The aim of the anthology is to decipher how age and ageing is done; here performing age, as in doing age, intersects with performances on stage. Theoretically this is inspired by Judith Butler, understanding the concept of gender as being repeatedly performed and learned, rather than something one is - or has. In the same way Ann Basting and Margaret Gullette look on age as an equally performed and learned identity: texts by them are theoretical inspirations for the anthology. A common denominator in several chapters is celebrity culture, exploring the tension between a star's persona and the different roles she is playing. Several of the chapters explore how a youth-fixated commercial film industry deals with ageing stars. In some chapters there are comparisons between for instance the casting of women and men - and these I find add to the strength of arguments in the book. Gender-bending - and age-bending helps develop a clearer understanding of contemporary conceptions and cultural constructions of ageing.

The book is divided into three sections. The first focuses on performances such as Helen Mirren as Queen Elizabeth II in the movie The Queen (2006). By combining her star persona as glamorous and modern in the role as an ageing queen, tensions between modernity and tradition are handled. The queen is portrayed also as a private person, a fragile grandmother who - in the turmoil after the death of the younger celebrity Princess Diana, Queen of hearts - manages to reconcile the wounded royal family with the indignant feelings of the public, in the narrative thus partaking in the recuperation of the monarchy.

Performance is also at the centre of Cristel Stalpert's interesting and moving chapter, which analyses different stage versions of Stravinskijs' The Rite of Spring, focusing on how casting of dancers in terms of gender and age impacts on the meaning of the ballet.

The second section focuses on ageing stars. In one chapter Estella Ticknell shows the interconnections between Goldie Hawn's persona, her different roles in movies and the symbiotic relationship between popular press and the movie industry. Goldie Hawn - in several roles and as persona - comes across as youthful, girlish, funny, naïve, but also as a dumb blonde. "Hawn's sexual star persona is, then, closely associated with the post-pill, non-maternal, recreationally available female body, even in self-parodic form" (p. 101). Hawn has managed to keep her career going 
as the ditzy blonde; the chapter pursues and problematizes how this image is managed in relation to ageing, showing that maturity must be denied in popular culture. Ticknell demonstrates how not just Hollywood but Western culture in general struggles with a limited conception of femininity, equalling beauty and sexuality with youth.

In a chapter on Sharon Stone's career, Rebecca Feasey discusses the actress's roles and her star image as a sexual femme fatale. When in the sequel to the box office success Basic Instinct Stone, then in her late forties, repeats this persona she is criticized and ridiculed. Feasey, referring to Ginn and Arber, claims that fear and derision of the ageing female has little to do with age in terms of lifestyle, behaviour or cultural norms, and more to do with visible signs of chronological ageing (p. 117). In popular press the failure of the movie sequel seems to have been ascribed to Stone due to her age, but was it because of her actual appearance? As far as Stone goes, it seems debatable if there were visible signs of ageing. The mere fact of her chronological age got attention, aptly illustrating that age also is a number.

The third section of the book contains three chapters, with the common theme stated to be ageing in a consumerist culture. There is for instance a chapter by Apostolos Poulios using conversation analysis on televised talk shows, where a number of Greek actors are expected to relate to their chronological age - some do this by denying it, and others by referring to acquired wisdom and experience. Stating correct birth date seemed to indicate authenticity but also courage, thus confirming that high age is a liability in this line of work.

In another chapter, Swinnen examines photographs by Erwin Olaf both a series of commercial shots advertising a jeans brand and a series of art photographs. In both series the photographer uses an older main character in a role commonly visually represented by a young, sexualised woman. Symbols and tropes are playfully used, making conceptions of ageing apparent to the viewer.

The book is enlightening, educating and entertaining, ranging from close readings of celebrities' careers, using movies and popular press as empirical material, to visual analyses of adverts and art photographs. The tension between youth, popular culture and especially female ageing is explored. The strength of the anthology is the close reading with 
International Journal of Ageing and Later Life

examples that illustrate how age is culturally given meaning in contemporary society. The chapters are well written, well argued, using interesting examples and references that help shed light on social meaning making of ageing.

The book is quite dense, both because it consists of chapters with different theoretical frameworks - ranging from psychoanalysis to film theory - and because of the large range of movies that are closely read in several chapters. But the impression of density is also due to the font size in relation to number of characters per line that gives it a compact, albeit academic impression. This is, in my opinion, a beauty flaw: more space in the layout would have been more reader friendly - and perhaps helped this book to reach even more readers in addition to the already committed and interested audience. I would recommend this readable book to those interested in film studies, celebrity studies, cultural studies, age studies and critical gerontology. 